\title{
Hyperostosis corticalis generalisata
}

INSERM

\section{Source}

INSERM. (1999). Orphanet: an online rare disease and orphan drug data base.

Hyperostosis corticalis generalisata. ORPHA:3416

Hyperostosis corticalis generalisata, also known as van Buchem disease, is a rare craniotubular hyperostosis characterized by hyperostosis of the skull, mandible, clavicles, ribs and diaphyses of the long bones, as well as the tubular bones of the hands and feet. Clinical manifestations include increased skull thickness with cranial nerve entrapment causing inconsistent cranial nerve palsies. 